\title{
Curcumin attenuates the effects of insulin on stimulating hepatic stellate cell activation by interrupting insulin signaling and attenuating oxidative stress
}

\author{
Jianguo Lin, Shizhong Zheng and Anping Chen
}

Hyperinsulinemia associated with type II diabetes mellitus (T2DM) is a risk factor for non-alcoholic steatohepatitis (NASH) and hepatic fibrosis. Hepatic stellate cells (HSCs) are the major effectors in collagen production during hepatic fibrogenesis. Elevated levels of insulin stimulate HSC activation. In addition to its anti-diabetic effects, the antioxidant curcumin, the yellow pigment in curry from turmeric, suppresses HSC activation and protects the liver from fibrogenesis in vitro and in vivo. This study aims at evaluating the effect of curcumin on insulin-induced HSC activation and further elucidating the underlying mechanisms. We report that curcumin dose-dependently eliminates insulin-induced HSC activation by suppressing expression of type I collagen gene and other key genes relevant to HSC activation. Additional experiments indicate that curcumin interrupts insulin signaling in HSCs by reducing the phosphorylation level of insulin receptor (InsR) and suppressing gene expression of InsR. Furthermore, curcumin attenuates insulin-induced oxidative stress in HSCs by inducing gene expression of glutamate-cysteine ligase (GCL), leading to de novo synthesis of glutathione and the suppression of gene expression of InsR. These results support our initial hypothesis that curcumin inhibits the effects of insulin on stimulating HSC activation by interrupting insulin signaling and attenuating oxidative stress. Our results provide novel insights into the mechanisms by which curcumin inhibits the insulin-induced HSC activation. Laboratory Investigation (2009) 89, 1397-1409; doi:10.1038/labinvest.2009.115; published online 19 October 2009

KEYWORDS: hepatic fibrosis; hepatic stellate cell; hyperinsulinemia; insulin; non-alcoholic fatty liver disease; phytochemical

Hyperinsulinemia, that is, abnormally elevated levels of plasma insulin, is a feature of type II diabetes mellitus (T2DM). T2DM is recognized as the etiology of over $80 \%$ of all diabetes and is dramatically increasing in incidence as a result of changes in human behavior and increased body mass index. ${ }^{1}$ Hyperinsulinemia is a condition in which normal amounts of insulin could not produce a normal insulin response from fat, muscle and liver cells. ${ }^{1,2}$ As a compensatory mechanism, pancreatic beta-cells excessively secret insulin to maintain euglycemia, resulting in abnormally elevated levels of blood insulin. ${ }^{3}$ Insulin in normal state carries out its functions through binding to insulin receptor (InsR), leading to the auto-phosphorylation of InsR and the activation of downstream signaling cascades, including the mitogen-activated protein kinase (MAPK) pathway and the PI3K-AKT pathway.

The liver is an insulin-sensitive organ that has a critical role in regulating the whole-body energy homeostasis. ${ }^{2}$ It has been noted that T2DM is often associated with non-alcoholic fatty liver diseases (NAFLDs) and is a risk factor for nonalcoholic steatohepatitis (NASH), an advanced form of NAFLD. ${ }^{5}$ NAFLDs are found in a quarter of the general population in the United States, and approximately 15-40\% of NASH patients develop hepatic fibrosis. ${ }^{6}$ Hepatic stellate cells (HSCs) are the key players in the development of hepatic fibrosis, regardless of etiology. ${ }^{7,8}$ HSCs normally lie in the space of Disse in a quiescent, non-proliferative state. They are characterized by abundant lipid droplets, composed of retinyl

Department of Pathology, School of Medicine, Saint Louis University, St Louis, MO, USA

Correspondence: A Chen, PhD, Department of Pathology, School of Medicine, Saint Louis University, 1100 South Grand Boulevard, Room 215, Edward A Doisy Research Center, St Louis, MO 63104, USA.

E-mail: achen5@slu.edu

Received 04 June 2009; revised 30 July 2009; accepted 10 August 2009 
esters, triglycerides, cholesteryl esters, cholesterol, phospholipids and free fatty acids. ${ }^{9,10}$ During hepatic injury, quiescent HSCs undergo profound phenotypic changes, including enhanced cell proliferation, loss of lipid droplets, de novo expression of $\alpha$-smooth muscle actin ( $\alpha$-SMA) and excessive production of ECM. This process is called HSC activation. Freshly isolated HSCs in culture gradually and spontaneously become fully activated in 7 days, ${ }^{11}$ mimicking the process observed in vivo, thus providing a good model for elucidating the underlying mechanisms of HSC activation and studying potential therapeutic intervention of the process. ${ }^{7,8}$ Studies have shown that insulin stimulates HSC activation in vitro by inducing mitogenesis and collagen synthesis. ${ }^{12}$

Despite considerable accomplishments in research on $\mathrm{NASH}$-associated hepatic fibrogenesis, the underlying mechanisms remain largely undefined. It is widely accepted that oxidative stress has critical roles in hepatic fibrosis, regardless of etiology. ${ }^{13}$ For instance, during the pathogenesis of NASH, fat accumulation in the liver is considered as 'the first hit, ${ }^{1}$ which makes the liver vulnerable to endotoxins and impairs liver regeneration. Oxidative stress is recognized as 'the second hit, ${ }^{1}$ which causes peroxidation of lipids in cell membranes, pro-inflammatory cytokine induction and the activation of HSCs. NASH patients have increased levels of oxidative stress and lipid peroxidation products, ${ }^{1,2}$ which, in turn, promotes the development of hepatic fibrogenesis. ${ }^{1,2}$ The activities of antioxidant enzymes in NASH patients are dramatically reduced. ${ }^{14}$ Oxidative stress stimulates collagen production in HSCs and hepatic fibrogenesis. ${ }^{14}$ Previous reports have shown protective effects of antioxidants, including vitamin $\mathrm{E}$, in the suppression of HSC activation $^{13}$ and the inhibition of hepatic fibrogenesis. ${ }^{13}$ However, the efficiency of currently well-known antioxidants in protecting the liver from fibrogenesis is still not very impressive. ${ }^{13,15}$

Few effective therapies are currently available for treatment of hepatic fibrosis. ${ }^{16}$ Research identifying anti-fibrotic agents that are innocuous is, therefore, of high priority and urgently needed. Curcumin, the yellow pigment in curry from turmeric, is a potent antioxidant, whose antioxidant capacity is 100 -fold stronger than vitamin E/C. ${ }^{17}$ Curcumin has received attention as a promising dietary component for the protection against fibrogenic insults. ${ }^{18}$ We recently showed that curcumin inhibited HSC activation, including inducing gene expression of endogenous peroxisome proliferator-activated receptor-gamma $(\mathrm{PPAR} \gamma)$ and suppressing gene expression of $\alpha \mathrm{I}(\mathrm{I})$ collagen, $\alpha$-SMA, PDGF- $\beta$ receptor (PDGF- $\beta \mathrm{R}$ ), EGF receptor (EGFR), type I and II transforming growth factor- $\beta$ receptors $(\mathrm{T} \beta$-RI and $\mathrm{T} \beta$-RII) and connective tissue growth factor (CTGF), and protected the liver from $\mathrm{CCl}_{4}$-caused fibrogenesis in vitro and in vivo. ${ }^{18-22}$ The current study aims at evaluating the effect of curcumin on eliminating the role of insulin in the stimulation of HSC activation and further elucidating the underlying mechanisms. Results in this report provide evidence to support our initial hypothesis that curcumin inhibits the effects of insulin on stimulating HSC activation by interrupting insulin signaling and attenuating oxidative stress.

\section{MATERIALS AND METHODS \\ Materials}

Insulin and curcumin (purity $>94 \%$ ) were purchased from Sigma-Aldrich (St Louis, MO, USA). Insulin was dissolved in $0.01 \mathrm{~N} \mathrm{HCl}$ and a stocking concentration at $1 \mathrm{mM}$ was prepared. Curcumin was dissolved in $100 \%$ ethanol and a stocking concentration at $100 \mathrm{mM}$ was made.

\section{HSC Isolation and Culture}

Hepatic stellate cells were isolated from the liver of normal male Sprague-Dawley rats (200-250 g) through portal vein perfusion with collagenase-pronase and subsequent density gradient centrifugation as previously described. ${ }^{11,20}$ After isolation, HSCs were identified by their typical morphology, the vitamin A-droplet-dependent auto-fluorescence and their inability to phagocytose latex beads. Freshly isolated HSCs were plated on plastic plates and cultured in Dulbecco's modified Eagle's medium (DMEM) supplemented with $20 \%$ fetal bovine serum (FBS) at $37^{\circ} \mathrm{C}$ in a $5 \% \mathrm{CO}_{2}$ atmosphere for the first $48 \mathrm{~h}$. The purity of HSCs was greater than $95 \%$, as assessed at $48 \mathrm{~h}$ after seeding. HSCs were subsequently cultured in regular DMEM with FBS (10\%). Semi-confluent HSCs with foureight passages were used in experiments. In some experiments, cells were cultured in serum-depleted media for $24 \mathrm{~h}$ before treatment, which rendered HSCs more sensitive to stimuli, including exogenous insulin. Cells were subsequently treated and cultured in serum-depleted media for additional $24 \mathrm{~h}$, which excluded the interference from other factors in FBS.

\section{Oil Red O Staining}

After fixation with $4 \%$ paraformaldehyde for $15 \mathrm{~min}$, HSCs were stained with Oil Red $\mathrm{O}$ in isopropanol $(60 \%)$ for $10 \mathrm{~min}$, followed by differentiation with isopropanol $(60 \%)$ for $2 \mathrm{~min}$. The cells were counterstained with hematoxylin for $15 \mathrm{~s}$ and washed with distilled water thoroughly. Lipid droplets in HSCs were evaluated using a light microscope with $\times 40$ amplification. Lipid droplets in quiescent HSCs were colored dark red by Oil Red O.

\section{mRNA Extraction and Real Time PCR}

Total RNA was extracted using TRI reagent according to the manufacturer's instruction (Sigma). Total RNA was treated with DNase I before the synthesis of the first strand of cDNA. Real-time PCR were performed as we previously described using SYBR Green Supermix. ${ }^{23}$ mRNA levels were expressed as fold changes after normalization with glyceraldehyde3-phosphate dehydrogenase (GAPDH), as described by Schmittgen et al. $^{24}$ The following primers were used for real-time PCR. InsR: (F) 5'-GCCTGGGCAACTGTTCAGA-3', (R) 5'-GTTTCGACAGGCCACACACTT-3'. Gclc: (F) 5'TGTGTGATGAGCCCAAGGAC-3'; (R) 5'-AGTTGGCTCGC ATCATAGTTG-3'; Gclm: (F) 5'-CTGCTAAACTGTTCAT 
TGTAGG-3'; (R) $5^{\prime}$-CTATGGGTTTTACCTGTG- ${ }^{\prime}$. Other primers were recently described. ${ }^{25}$

\section{Western Blotting Analyses}

Whole cell extracts were prepared as we previously described. ${ }^{20}$ Protein concentrations were determined using the BCA Protein Assay Kit according to the manufacturer's instruction (Pierce, Rockford, IL, USA). SDS-PAGE, transblotting and subsequent immunoreactions were conducted as we previously described. ${ }^{20}$ The antibodies used in this study are described in Table 1.

\section{Determination of the Level of Intracellular Reactive Oxygen Species (ROS)}

The level of intracellular ROS in HSCs was determined by analyzing dichlorofluorescein (DCF) fluorescence, as described previously. ${ }^{26}$

\section{Table 1 Antibodies used for Western blotting analyses}

\begin{tabular}{|c|c|c|}
\hline Company & Description & Catalog number \\
\hline Santa Cruz & Rabbit $\alpha$-PDGF- $\beta$ R antibody & sc-432 \\
\hline \multirow[t]{23}{*}{ Biotechnology, Inc. } & Rabbit $\alpha$-EGFR antibody & Sc-03 \\
\hline & Rabbit $\alpha$-T $\beta$-RII antibody & Sc-400 \\
\hline & Rabbit $\alpha-T \beta$-RI antibody & Sc-399 \\
\hline & Rabbit $\alpha$-p27 antibody & Sc-528 \\
\hline & Rabbit $\alpha$-p21 antibody & Sc-397 \\
\hline & Rabbit $\alpha$-Bax antibody & Sc-493 \\
\hline & Rabbit $\alpha-\mathrm{Bcl}-2$ antibody & Sc-492 \\
\hline & Rabbit $\alpha$-InsR antibody & Sc-20739 \\
\hline & Rabbit $\alpha$-p-InsR antibody & Sc-25103-R \\
\hline & Rabbit $\alpha-p-E R K 1 /$ antibody & Sc-16982-R \\
\hline & Rabbit $\alpha$ - total ERK1 antibody & Sc-94 \\
\hline & Rabbit $\alpha$-total ERK2 antibody & Sc-153 \\
\hline & Rabbit $\alpha$-p-AKT ${ }^{\text {ser }} 473$ antibody & Sc-7985-R \\
\hline & Rabbit $\alpha$-total AKT antibody & Sc-8312 \\
\hline & Rabbit $\alpha$-p-JNK antibody & Sc-12882-R \\
\hline & Rabbit $\alpha$-total JNK antibody & Sc-474 \\
\hline & Rabbit $\alpha-p-P \mid 3 K$ antibody & Sc-12929-R \\
\hline & Rabbit $\alpha$-total PI3K antibody & Sc-423 \\
\hline & Goat $\alpha$-CTGF antibody & Sc-14939 \\
\hline & Goat $\alpha$-pro- $\alpha$ l(I)col antibody & Sc-25974 \\
\hline & Bovine $\alpha$-goat-lgG-HRP & Sc-2350 \\
\hline & Goat $\alpha$-mouse-lgG-HRP & Sc-2005 \\
\hline & Goat $\alpha$-rabbit-lgG-HRP & Sc-2004 \\
\hline \multirow[t]{2}{*}{ Sigma } & $\begin{array}{l}\text { Mouse } \alpha \text {-alpha-SMA monoclonal } \\
\text { antibody }\end{array}$ & A2547 \\
\hline & Rabbit $\alpha-\beta$-actin antibody: & A2066 \\
\hline
\end{tabular}

\section{Lipid Peroxide (LPO) Assays}

LPO assays were performed using the lipid hydroperoxide assay kit purchased from Cayman Chemical (Ann Arbor, MI, USA).

\section{Glutathione (GSH) Assays}

The levels of GSH and GSSG were determined by the glutathione assay kit from Cayman Chemical, following the protocol provided by the manufacturer. The concentration of total GSH was calculated according to the equation in the protocol.

\section{Analyses of Glutamate-Cysteine Ligase (GCL) Activities} Glutamate-cysteine ligase activities were spectrophotometrically determined as previously described with slight modifications. ${ }^{27}$ In brief, a sample of cell extracts $(20 \mu \mathrm{l})$ was mixed with the reaction solution $(0.21 \mathrm{ml})$ containing Tris-HCl (100 mM), pH 8.0, $\mathrm{KCl}(150 \mathrm{mM}), \mathrm{MgCl}_{2}(20 \mathrm{mM})$, $\mathrm{Na}_{2}$ EDTA $(2 \mathrm{mM}), \mathrm{Na}_{2} \mathrm{ATP}(5 \mathrm{mM})$, phosphoenolpyruvate $(2 \mathrm{mM})$, L-glutamate $(10 \mathrm{mM}), \mathrm{L}-\alpha$-aminobutyrate $(10 \mathrm{mM})$, $\mathrm{NADH}(0.27 \mathrm{mM})$, type II rabbit muscle pyruvate $(2 \mu \mathrm{g})$ and lactate dehydrogenase $(2 \mu \mathrm{g})$. The reaction was initiated by the addition of ATP to a final concentration at $5 \mathrm{mM}$. The decrease in the absorbance of NADH at $340 \mathrm{~nm}$ was monitored for $30 \mathrm{~min}$ with an interval of $2 \mathrm{~min}$ using a SpectraMax 190 plate reader (Molecular Device, Sunnyvale, CA, USA) and expressed as $\mu \mathrm{mol}$ of NADH oxidized/min. Protein concentration was quantitated using BCA assay (Pierce). The final GCL activity was calculated and expressed as $\mu \mathrm{mol}$ of $\mathrm{NADH}$ oxidized/min per mg protein.

\section{Statistical Analyses}

The differences between means were evaluated using an unpaired two-sided Student's $t$-test $(P<0.05$ considered as significant). Where appropriate, comparisons of multiple treatment conditions with controls were analyzed using ANOVA with the Dunnett's test for post hoc analysis.

\section{RESULTS}

Curcumin Eliminates the Effects of Insulin on Regulating Expression of Genes Closely Relevant to HSC Activation in Culture-Activated HSCs

Previous studies have shown that insulin stimulates HSC activation in vitro by inducing mitogenesis and collagen synthesis. ${ }^{12}$ To evaluate the effect of curcumin on insulininduced HSC activation, semi-confluent HSCs, after being cultured in serum-depleted media for $24 \mathrm{~h}$, were stimulated with insulin $(100 \mathrm{nM})$ in the presence of curcumin at $0-30 \mu \mathrm{M}$ in serum-depleted DMEM for additional $24 \mathrm{~h}$. Results from our pilot experiments indicated that compared with serum-starved HSCs, HSCs cultured in regular DMEM with FBS (10\%) required higher concentrations of insulin to achieve the same level of changes in regulating expression of genes, including $\alpha \mathrm{I}(\mathrm{I})$ collagen and $\alpha$-SMA, the two established markers for activated HSCs (data not shown). These observations suggested that serum starvation rendered HSCs 
in vitro more sensitive to exogenous stimuli. The subsequent culture in serum-depleted media excluded the interference from other factors in FBS. ${ }^{21,28}$ Total RNA and whole cell extracts were prepared from the cells. To evaluate the effects of curcumin on insulin-induced cell growth, genes relevant to cell proliferation and to apoptosis were selectively studied. As shown by real-time PCR assays (Figure 1a), compared with the untreated control (the corresponding first columns), insulin significantly increased, as expected, the mRNA levels of pro-mitogenic PDGF- $\beta$ R and EGFR (the corresponding second columns), and reduced the mRNA levels of the potent cyclin-dependent kinase inhibitors $\mathrm{p} 21^{\mathrm{Cip} 1}$ and $\mathrm{p} 27^{\mathrm{Kip} 1}$ (the corresponding second columns). In addition, insulin increased the mRNA level of anti-apoptotic protein $\mathrm{Bcl}-2$ and reduced the mRNA level of pro-apoptotic protein Bax in the cells (the corresponding second columns). Further experiments indicated that curcumin dose-dependently eliminated the insulin effects (the corresponding 3-6 columns). These observations were verified using Western blotting analyses (Figure 1b).

To assess the effect of curcumin on insulin-induced fibrogenesis, genes relevant to fibrogenesis were selectively studied. Real-time PCR (Figure 1c) and Western blotting analyses (Figure 1d) showed that compared with the untreated control (the corresponding first columns or wells), insulin stimulated, as expected, gene expression of $\alpha$-SMA and $\alpha \mathrm{I}(\mathrm{I})$ collagen, the markers of activated HSCs, and profibrogenic T $\beta$-RI and T $\beta$-RII and CTGF (the corresponding second columns or well). The stimulatory effects of insulin were dose-dependently attenuated by curcumin (the corresponding 3-6 columns). It is noteworthy that insulin suppressed gene expression of PPAR $\gamma$ in cultured HSCs (Figures 1c and d). Curcumin dose-dependently abrogated the inhibitory role of insulin and induced gene expression of endogenous PPAR $\gamma$, which had been shown to have a critical role in the curcumin-caused inhibition of HSC activation. ${ }^{20,21}$ Taken together, our results suggested that curcumin eliminated the effects of insulin on stimulating HSC activation in vitro.

\section{Insulin Stimulates the Activation of Quiescent HSCs In Vitro, Which is Attenuated by Curcumin}

To evaluate the effect of insulin on the activation of quiescent HSCs and the potential inhibitory role of curcumin in the

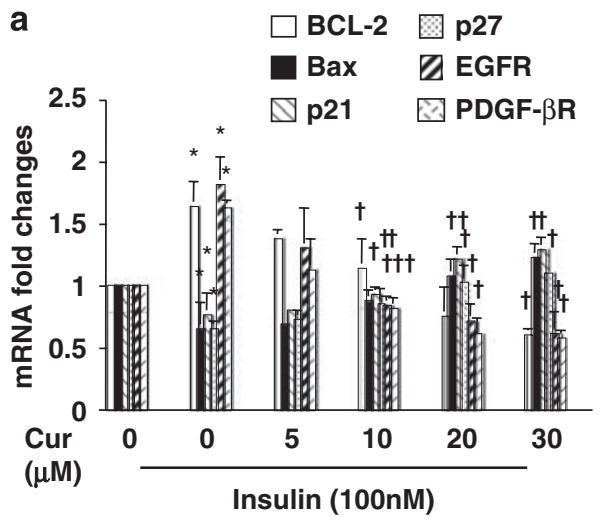

b
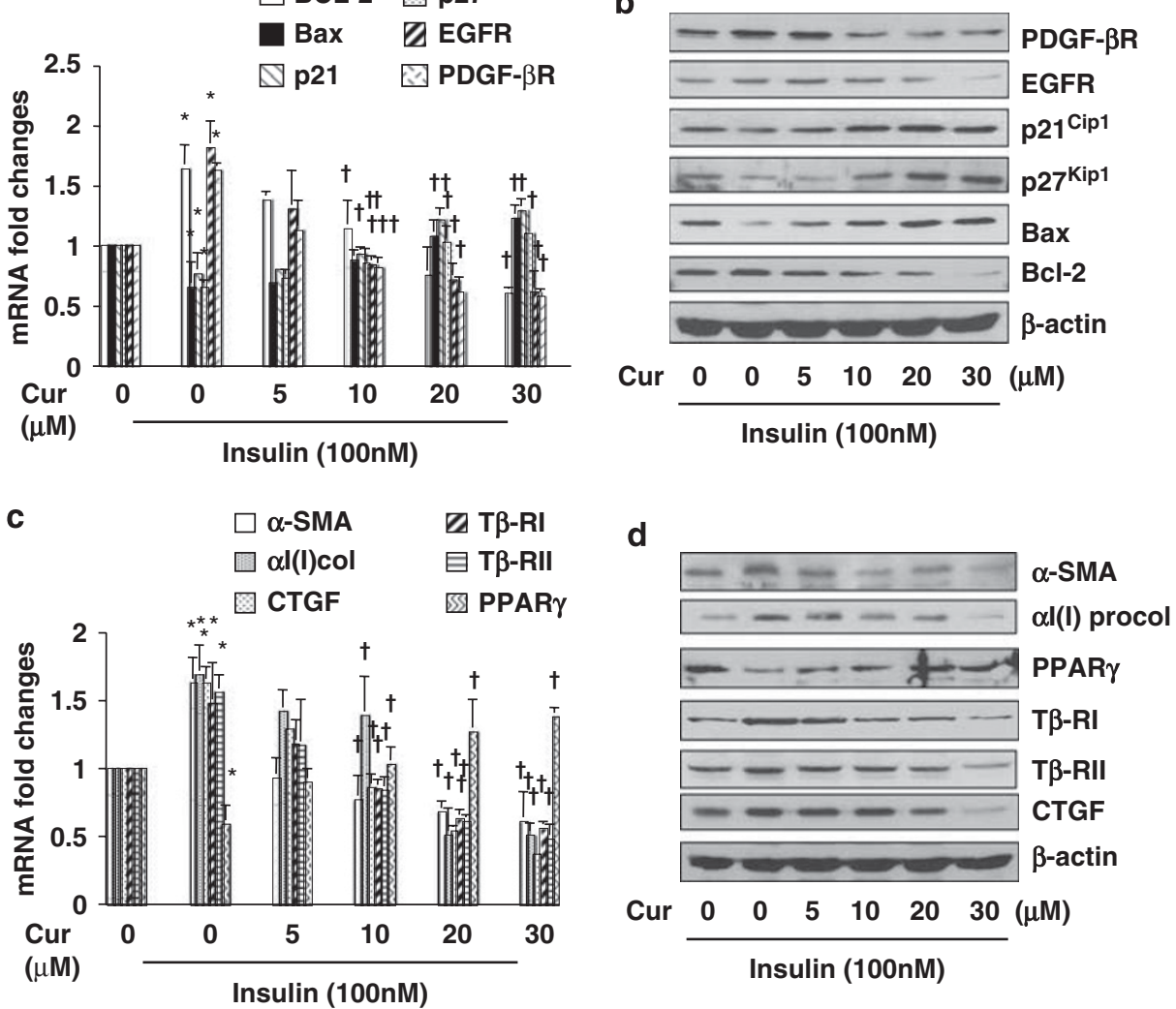

Figure 1 Curcumin attenuates the stimulatory effects of insulin on the activation of HSCs. Serum-starved HSCs were stimulated with or without insulin $(100 \mathrm{nM})$ and curcumin at various concentrations in serum-depleted DMEM for $24 \mathrm{~h}$. Total RNA or whole cell extracts were prepared for real-time PCR assays $(\mathbf{a}, \mathbf{c})$, or for Western blotting analyses $(\mathbf{b}, \mathbf{d})$. Values in $\mathbf{a}$ and $\mathbf{c}$ were presented as mRNA fold changes (mean \pm s.d., $n=3$ ), ${ }^{\star} P<0.05$, versus the untreated control (the corresponding first columns); ${ }^{\dagger} P<0.05$, versus cells treated with insulin only (the corresponding second columns). Blots were representatives from three independent experiments. $\beta$-actin was used as an internal control for equal loading for Western blotting analyses. (a, b) Analyses of expression of genes relevant to cell proliferation or apoptosis and $(\mathbf{c}, \mathbf{d})$ analyses of expression of genes relevant to fibrogenesis. 
process, additional experiments were conducted. After culturing for $24 \mathrm{~h}$ in serum-rich media $(20 \% \mathrm{FBS})$ for cell attachment, freshly isolated quiescent HSCs were cultured in DMEM with $10 \% \mathrm{FBS}$, or $2 \% \mathrm{FBS}$ and insulin $(100 \mathrm{nM})$ with or without curcumin at 5 or $10 \mu \mathrm{M}$ for additional 1,3 or 5 days. These HSCs were stained with Oil Red O for detecting intracellular lipid droplets. As shown in Figure 2, after 1-day culture, regardless of the supplements in the media with or without curcumin, HSCs showed high levels of intracellular lipid droplets, which were stained dark red by Oil Red O, demonstrating that these HSCs were still in quiescent state. Insulin $(100 \mathrm{nM})$ and $2 \%$ FBS, similar to FBS (10\%), daydependently and apparently reduced the contents of lipid droplets in HSCs, suggesting that insulin, similar to FBS, stimulated the activation of HSCs in culture. Most of freshly isolated quiescent HSCs were detached within 3 days in the media with only $2 \%$ FBS (data not shown). In great contrast, the presence of curcumin in the media with insulin and $2 \%$ FBS dose-dependently maintained higher levels of intracellular lipid droplets after 5 days of culture, suggesting that curcumin attenuated the stimulatory role of insulin, which might delay the process of HSC activation in culture. Lower concentrations of curcumin at 5 and $10 \mu \mathrm{M}$ were used because of the higher sensitivity of freshly isolated HSCs to the phytochemical. Most of the cultured cells were detached within 7 days in the media with insulin $(100 \mathrm{nM})$ and $2 \%$ FBS in the presence of curcumin (data not shown). Quiescent HSCs were reported to become fully activated after 7 days of culture in DMEM with 10\% FBS. ${ }^{11}$ However, the technical barrier prevented us from conducting the experiments for more than 5 days. Taken together, our results showed that insulin stimulated the activation of quiescent HSCs in vitro, which was attenuated by curcumin.

\section{Curcumin Reduces the Phosphorylation of InsR and Its Downstream Inter-Mediators in HSCs}

To explore the underlying mechanisms by which curcumin eliminated the insulin-induced HSC activation, we hypothesized that curcumin might interrupt insulin signaling pathways, which was initiated by binding of insulin to its receptor InsR, leading to the auto-phosphorylation of the receptor and the subsequent activation of downstream signaling inter-mediators, including ERK, JNK, PI3K and AKT. ${ }^{4}$ Pilot experiments indicated that insulin rapidly initiated its signaling by stimulating the phosphorylation of InsR in HSCs, which reached its peak within $20-30 \mathrm{~min}$ and

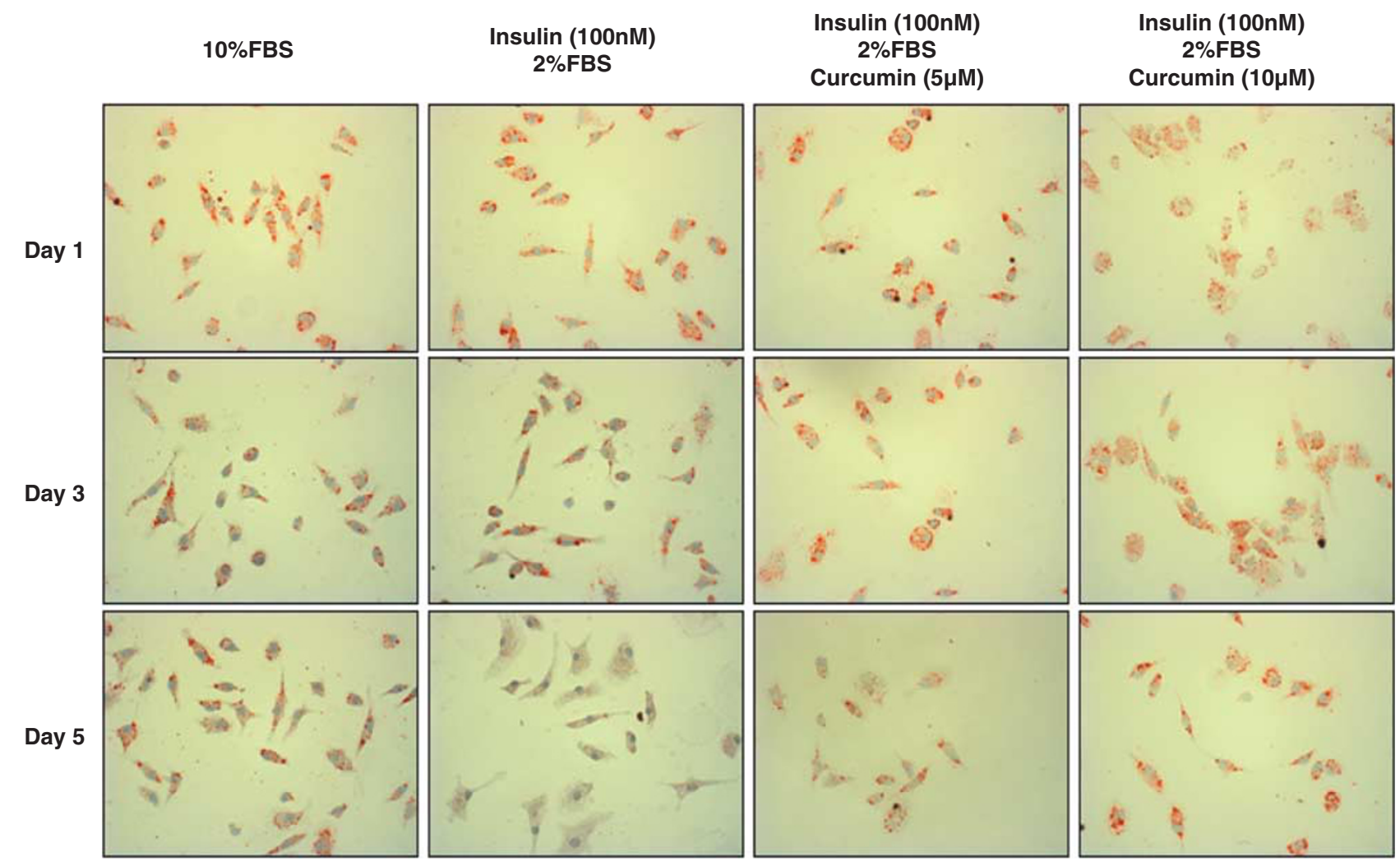

Figure 2 Insulin stimulates the activation of quiescent HSCs in vitro, which is attenuated by curcumin. After culturing for $24 \mathrm{~h}$ in serum-rich media (20\%FBS) for cell attachment, freshly isolated HSCs were cultured in DMEM with $10 \%$ FBS, or $2 \%$ FBS and insulin (100 nM) with or without curcumin at indicated concentrations for additional 1, 3 or 5 days. Each treatment had triplicates. After fixation, the cells were stained with Oil Red O for detecting intracellular lipid droplets, which were colored dark red by Oil Red O. Representative views were presented. 


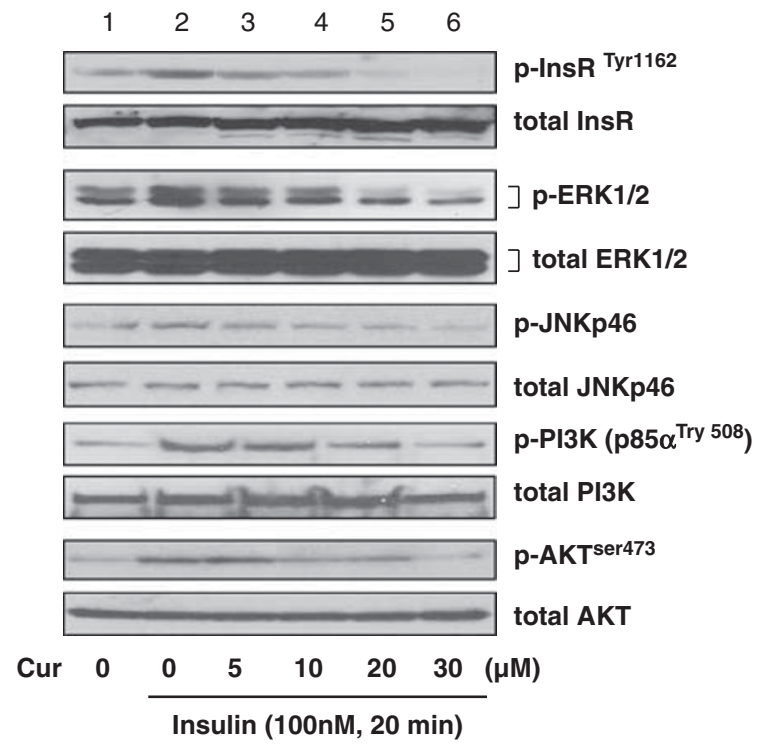

Figure 3 Curcumin reduces phosphorylation levels of InsR and its downstream signaling inter-mediators in HSCs. Serum-starved HSCs were pretreated with curcumin for $1 \mathrm{~h}$ at various concentrations before stimulation with insulin $(100 \mathrm{nM})$ for additional $20 \mathrm{~min}$. Whole cell extracts were prepared for Western blotting analyses of phosphorylated proteins and their corresponding total proteins. The total protein for each corresponding phospho-protein was used as the internal control for equal loading. Representatives were shown from three independent experiments.

gradually faded thereafter (data not shown here). To evaluate the effect of curcumin on insulin signaling pathways, serum-starved HSCs were pretreated with curcumin at various concentrations for $1 \mathrm{~h}$ before stimulation with insulin $(100 \mathrm{nM})$ in serum-depleted DMEM for additional $20 \mathrm{~min}$. The pretreatment with curcumin inhibited activating signal pathways and excluded their interference. Whole cell extracts were prepared. As shown in Figure 3, using Western blotting analyses insulin significantly increased the abundance of phosphorylated InsR $^{\text {Tyr }}{ }^{1162}$, ERK1/2, JNKp46, PI3K (p85 $\alpha^{\text {Tyr }}{ }^{508}$ ) and $\mathrm{AKT}^{\mathrm{ser}} 473$ (the corresponding second wells) in cultured HSCs when compared with the untreated control (the corresponding first wells). The insulin stimulatory effects were dosedependently attenuated by curcumin (the corresponding 2-6 wells), indicating that curcumin interrupted the insulin signaling pathways. It is noteworthy that the phosphorylation of InsR and its downstream inter-mediators was an instant and shortterm action after insulin stimulation. The effect of curcumin on it was a short-term event, which lasted only for a few hours.

\section{Curcumin Dose-Dependently Suppresses Gene Expression of InsR in Cultured HSCs}

To further explore the mechanisms by which curcumin eliminated the stimulatory effects of insulin on the activation of HSCs, we assumed that in addition to the instant and short-term action, curcumin should exert a slow but longlasting action. We postulated that curcumin suppressed gene
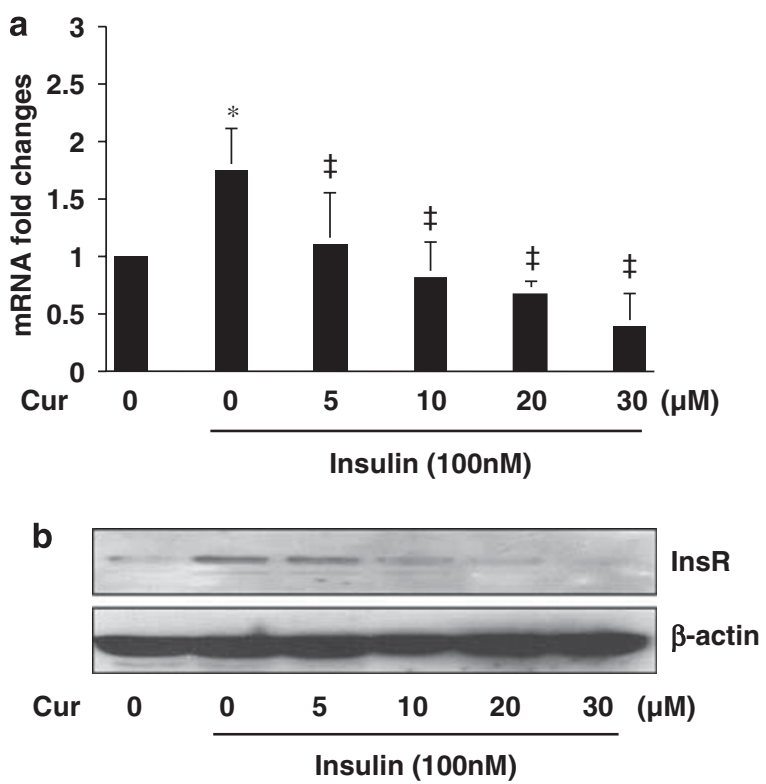

Figure 4 Curcumin dose-dependently suppresses gene expression of InsR in cultured HSCs. Serum-starved HSCs were stimulated with or without insulin $(100 \mathrm{nM})$ in the presence or absence of curcumin at indicated concentrations in serum-free media for $24 \mathrm{~h}$. Total RNA or whole cell extracts were prepared. (a) Real-time PCR assays of the steady-state level of InsR mRNA. $\beta$-actin was used as an invariant internal control for calculating mRNA fold changes $(n=3) .{ }^{*} P<0.05$ versus cells with no treatment (the first column on the left); ${ }^{\ddagger} P<0.05$ versus cells treated with insulin only (the second column on the left). (b) Western blotting analyses of the abundance of InsR. $\beta$-actin was used as an internal control for equal loading. A representative was shown from three independent experiments.

expression of InsR, leading to a reduction in the bioavailability of InsR to insulin. To test this postulation, serumstarved HSCs were stimulated with insulin at $100 \mathrm{nM}$ in the presence of curcumin at $0-30 \mu \mathrm{M}$ in serum-depleted media for $24 \mathrm{~h}$. Total RNA and whole cell extracts were prepared for analyses of gene expression of InsR. As shown in Figure 4, using real-time PCR and Western blotting analyses insulin significantly increased the steady-state level of transcript and the abundance of protein of InsR (the second column or well) when compared with the untreated control (the first column or well). The stimulatory effects were dose-dependently abolished by curcumin (the 3-6 columns or wells). Taken together, these results supported our postulation and showed that curcumin suppressed gene expression of InsR in activated HSCs in vitro.

\section{Insulin Increases the Levels of Intracellular ROS and LPO in HSCs, Which is Dose-Dependently Attenuated by Curcumin}

Oxidative stress has been known to have a critical role in HSC activation and in hepatic fibrogenesis, regardless of etiology. ${ }^{13,29}$ We have previously reported the role of curcumin alone in attenuating oxidative stress in cultured HSCs. ${ }^{23}$ To explore the mechanisms by which insulin stimulated the 
a

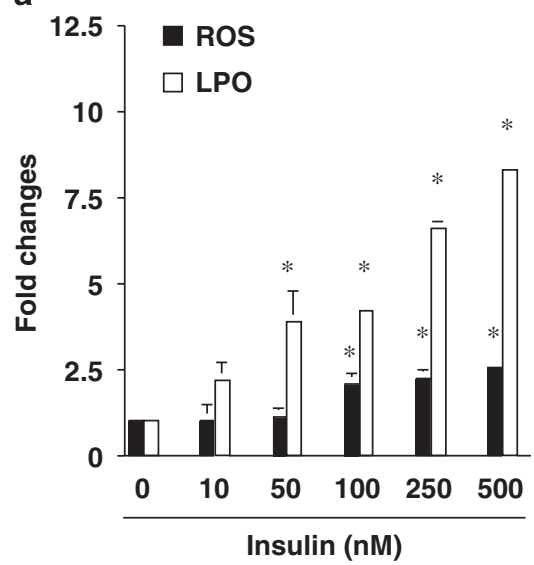

b

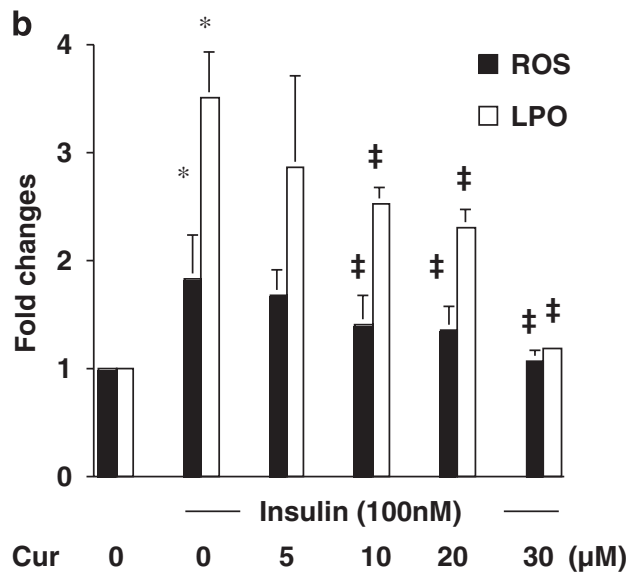

Figure 5 Insulin stimulates oxidative stress in cultured HSCs by increasing the levels of ROS and LPO, which is attenuated by curcumin. Serum-starved HSCs were stimulated with insulin at indicated concentrations in the absence (a) or presence (b) of curcumin at 0-30 $\mu \mathrm{M}$ in serum-free media for $24 \mathrm{~h}$. The levels of intracellular ROS and LPO were assessed and expressed as fold changes compared with cells with no treatment (the first column on the left). Values were presented as means \pm s.d. $(n \geq 3)$. ${ }^{\star} P<0.05$, versus cells with no treatment; ${ }^{\ddagger} P<0.05$, versus cells treated with insulin only (the second column on the left in $\mathbf{b}$ ).

activation of HSCs, experiments were conducted to evaluate the effect of insulin on oxidative stress. Serumstarved HSCs were stimulated with different concentrations of insulin in serum-depleted media for $24 \mathrm{~h}$. The levels of LPO and ROS in the cells were determined. As shown in Figure 5a, insulin elevated the levels of cellular ROS and LPO in a dose-dependent manner. To assess the role of curcumin in attenuating insulin-induced oxidative stress, serum-starved HSCs were stimulated with insulin $(100 \mathrm{nM})$ in the presence or absence of curcumin at indicated concentrations in serum-depleted media for $24 \mathrm{~h}$. As shown in Figure 5b, ROS and LPO levels elevated by insulin in the cells were dose-dependently reduced by curcumin. These results collectively indicated that insulin induced oxidative stress in cultured HSCs, which was attenuated by curcumin.

\section{Curcumin Attenuates Insulin-Induced Oxidative Stress in Activated HSCs, at Least Partially, by Increasing the Level of Intracellular GSH and Improving the Ratio of GSH/GSSG}

Glutathione is the most abundant and effective thiol antioxidant in eukaryotic cells. ${ }^{30} \mathrm{GSH}$ is converted to its oxidized form (GSSG), when attenuating oxidative stress. ${ }^{30}$ To elucidate the mechanisms by which insulin induced oxidative stress and curcumin attenuated the insulin-induced oxidative stress, serum-starved HSCs were stimulated with insulin at indicated concentrations in the presence or absence of curcumin at various concentrations in serum-depleted media for $24 \mathrm{~h}$. As shown in Figures $6 \mathrm{a}$ and $\mathrm{c}$, insulin reduced, in a dose-dependent manner, the levels of intracellular GSH and the ratio of GSH/GSSG, a sensitive indicator of oxidant stress. $^{31,32}$ On the other hand, curcumin dose-dependently eliminated the inhibitory effects of insulin on the level of cellular GSH (Figure 6b) and improved the ratio of GSH/ GSSG (Figure 6d). These results indicated that curcumin attenuated insulin-induced oxidative stress in activated HSCs, at least partially, by increasing the level of intracellular GSH and improving the ratio of GSH/GSSG.

\section{Curcumin Increases the Level of Cellular GSH and Attenuates Insulin-Induced Oxidative Stress in Activated HSCs In Vitro by Stimulating the Activity of GCL}

The level of cellular GSH is mainly determined by GSH synthesis (GSH supply) and GSH-consuming (GSH demand). GCL is the key rate-limiting enzyme in de novo synthesis of GSH. ${ }^{27}$ To understand the mechanisms by which insulin reduced the levels of cellular GSH and curcumin eliminated the inhibitory effects, we assumed that insulin might reduce the GCL activity in HSCs, which was eliminated by curcumin. To test the assumption, serum-starved HSCs were stimulated with insulin at indicated concentrations in the presence or absence of curcumin at various doses in serum-free media for $24 \mathrm{~h}$. Whole cell extracts were prepared for analyzing the GCL activity. The results in Figure 7a showed that insulin dose-dependently reduced the activity of GCL in these cells. The inhibitory effect of insulin was eliminated by curcumin (Figure $7 \mathrm{~b}$ ). For example, compared with the control cells treated with insulin only (the second column in Figure $7 \mathrm{~b}$ ), curcumin at $20 \mu \mathrm{M}$ abrogated the inhibitory effect of insulin and caused a significant increase in the activity of GCL by $60.8 \%$. Taken together, these results supported our assumption and showed that curcumin increased the level of cellular GSH and attenuated insulin-induced oxidative stress in activated HSCs in vitro by stimulating the activity of GCL. 

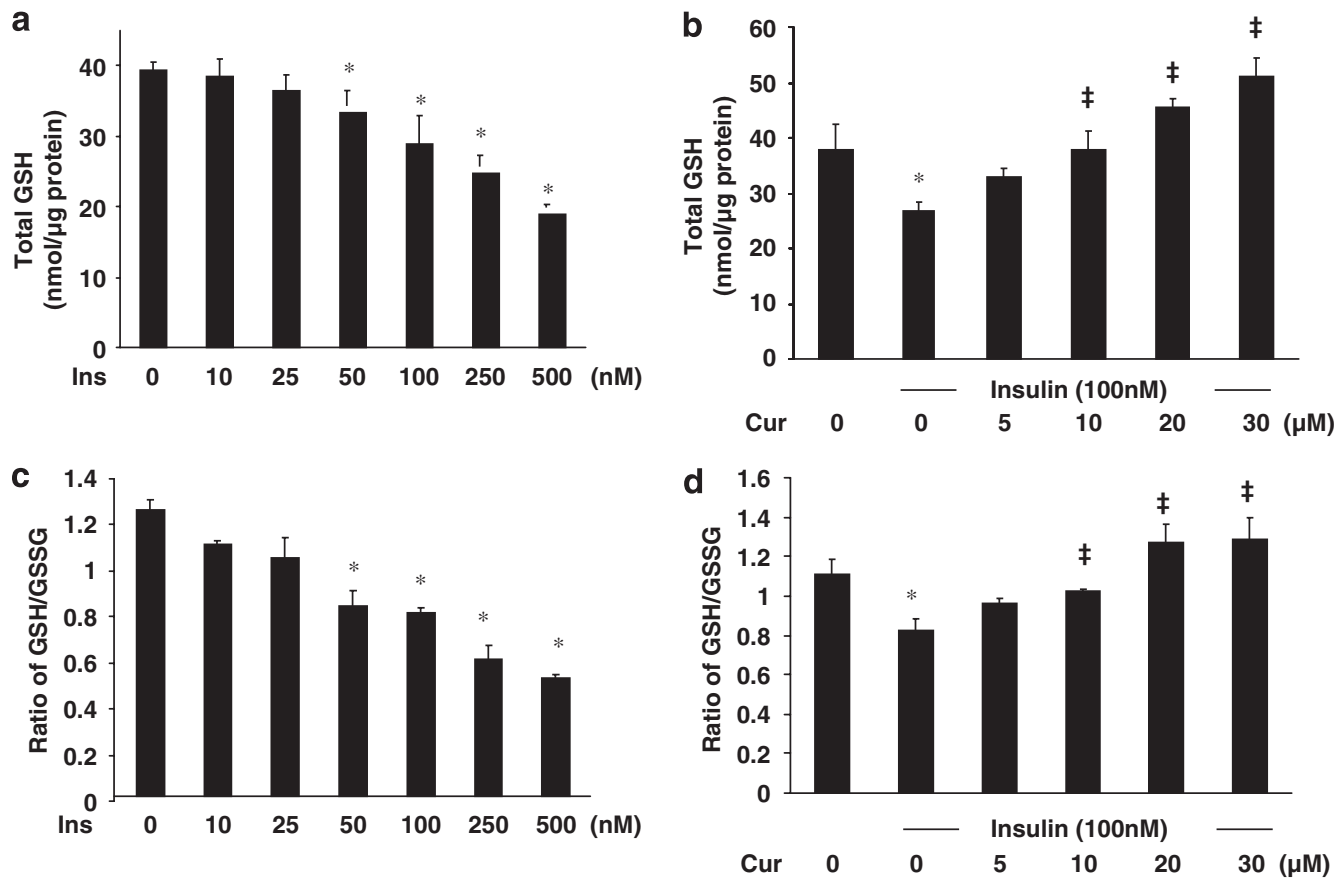

Figure 6 Insulin reduces the level of intracellular GSH and the ratio of GSH/GSSG in cultured HSCs, which are dose-dependently eliminated by curcumin. Serum-starved HSCs were stimulated with insulin at indicated concentrations in the absence $(\mathbf{a}, \mathbf{c})$ or presence $(\mathbf{b}, \mathbf{d})$ of curcumin at 0-30 $\mu \mathrm{M}$ in serum-free media for $24 \mathrm{~h}$. The levels of total cellular GSH $(\mathbf{a}, \mathbf{b})$ and the ratio of GSH/GSSG (c, $\mathbf{d})$ were determined. The levels of total GSH were expressed as $\mathrm{nmol} / \mu \mathrm{g}$ protein. Values were presented as means \pm s.d. $(n \geq 3)$. ${ }^{\star} P<0.05$, versus cells with no treatment (the first column on the left). ${ }^{\ddagger} P<0.05$, versus cells treated with insulin only (the second column on the left in $\mathbf{b}, \mathbf{d}$ ).
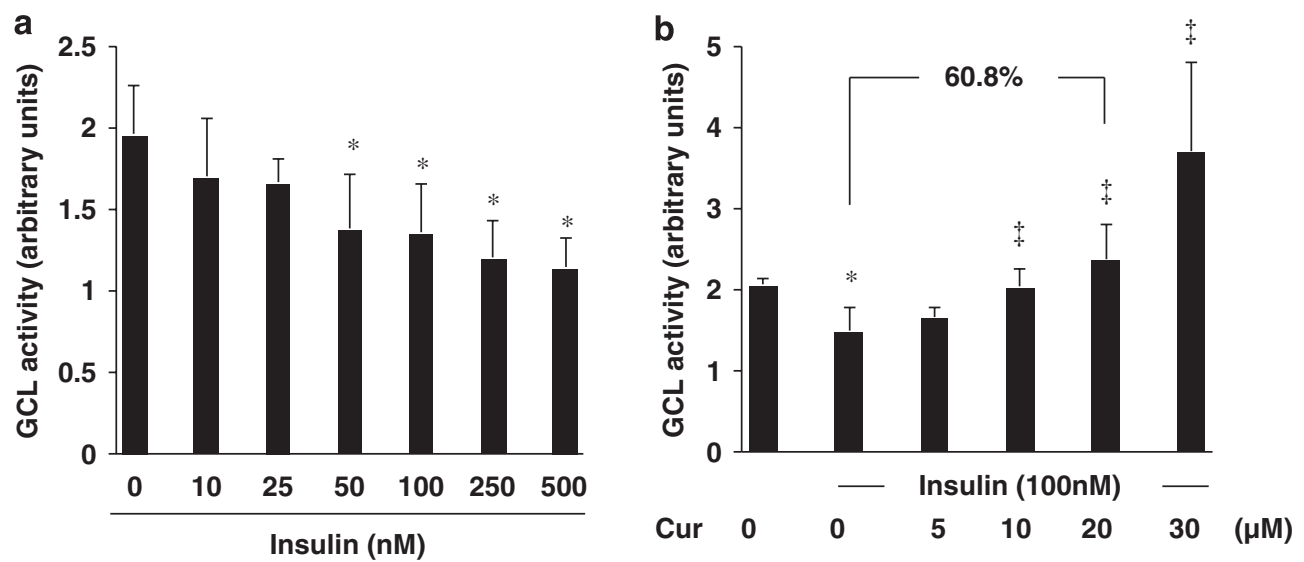

Figure 7 Curcumin eliminates the role of insulin in the reduction of the activity of GCL in activated HSCs in vitro. Serum-starved HSCs were stimulated with insulin at indicated concentrations in the absence (a) or presence (b) of curcumin at $0-30 \mu \mathrm{M}$ in serum-free media for $24 \mathrm{~h}$. The activities of GCL in the cells were determined. Values were expressed as means \pm s.d. $(n \geq 6)$. The number of percentage indicates the increase in the $\mathrm{GCL}$ activity in cells treated with insulin $(100 \mathrm{nM})$ and curcumin $(20 \mu \mathrm{M})$ compared with cells treated with insulin only. ${ }^{\star} P<0.05$, versus cells with no treatment (the first column on the left). ${ }^{\ddagger} P<0.05$, versus cells treated with insulin only (the second column on the left in $\mathbf{b}$ ).

\section{Curcumin Increases the Activity of GCL and the Level of Cellular GSH in Insulin-Activated HSCs by Inducing Gene Expression of GCLC and GCLm}

The enzyme of GCL is composed of a large catalytic subunit (GCLc, $\sim 73 \mathrm{kDa}$ ) and a small modulatory subunit (GCLm, $\sim 30 \mathrm{kDa}$ ). To answer the question of how curcumin could increase the activity of GCL and elevate the level of cellular GSH in insulin-activated HSCs, we postulated that curcumin might induce gene expression of the GCL subunits GCLc and GCLm, leading to the increase in the GCL activity and the elevation of the level of cellular GSH. To test the postulation, serum-starved HSCs were stimulated with insulin at various 


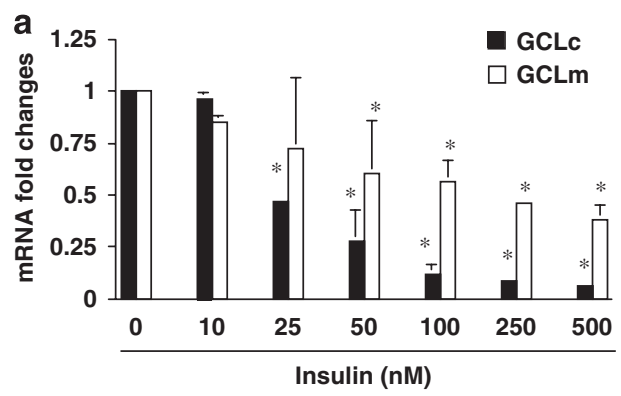

c

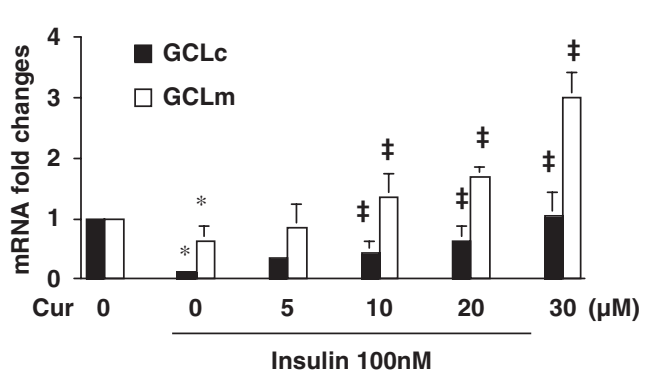

b

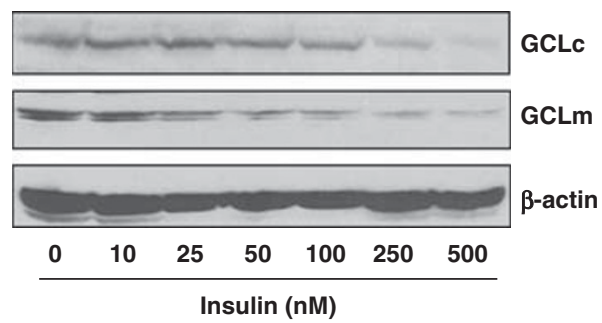

d

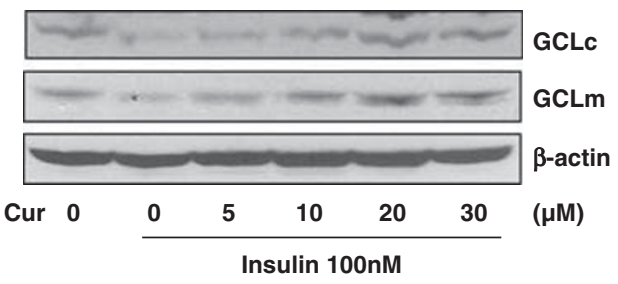

Figure 8 Curcumin eliminates the effect of insulin and induces gene expression of GCLc and GCLm in activated HSCs in vitro. Serum-starved HSCs were stimulated with insulin at indicated concentrations in the absence $(\mathbf{a}, \mathbf{b})$ or presence $(\mathbf{c}, \mathbf{d})$ of curcumin at 0-30 $\mu \mathrm{M}$ in serum-free media for $24 \mathrm{~h}$. Total RNA or whole cell extracts were prepared for real-time PCR assays $(\mathbf{a}, \mathbf{c})$ or Western blotting analyses $(\mathbf{b}$, $\mathbf{d})$. $\beta$-actin was used as an invariant internal control for calculating mRNA fold changes $(n=3)$. ${ }^{*} P<0.05$, versus cells with no treatment (the corresponding first column on the left in a, c); ${ }^{\ddagger} P<0.05$, versus cells treated with insulin only (the corresponding second column on the left in $\mathbf{a}, \mathbf{c}) . \beta$-actin was used as an internal control for equal loading (b, d). A representative was shown from three independent experiments.

concentrations in the presence or absence of curcumin at indicated doses in serum-depleted media for $24 \mathrm{~h}$. Total RNA and whole cell extracts were prepared from the cells. Gene expression of GCLc and GCLm were analyzed using real-time PCR and Western blotting analyses. It was observed that insulin reduced the levels of GCLc and GCLm transcripts (Figure $8 \mathrm{a}$ ) and proteins (Figure $8 \mathrm{~b}$ ). The inhibitory effect of insulin was dose-dependently abrogated by curcumin (Figures $8 \mathrm{c}$ and $\mathrm{d}$ ). These results supported our postulation and showed that curcumin increased the activity of GCL and elevated the level of cellular GSH in insulin-activated HSCs by inducing gene expression of GCLc and GCLm.

\section{De Novo Synthesis of GSH is Required for Curcumin to Inhibit Gene Expression of InsR and Other Key Proteins Relevant to HSC Activation Induced by Insulin}

To elucidate the mechanisms by which curcumin inhibited InsR gene expression in HSCs, we presumed that the elevation of the level of cellular GSH had a critical role in the curcumin-dependent suppression of expression of InsR gene and other genes relevant to HSC activation, as observed in Figures 1 and 4. To test this presumption, levels of cellular GSH in cultured HSCs were altered by the following wellknown manipulators of GSH synthesis. $\mathrm{N}$-acetyl-cysteine (NAC) is a precursor of GSH and increases GSH contents by supplying cysteine. ${ }^{33} \mathrm{~L}$-Buthionine sulfoximine (BSO) is a specific inhibitor of GCL, which depletes cellular GSH. ${ }^{34}$ We previously showed that BSO alone caused a time- and dosedependent reduction in the level of GSH in cultured HSCs. ${ }^{23}$ Serum-starved HSCs were divided into two groups. In one group, cells were stimulated with or without insulin $(100 \mathrm{nM})$ and curcumin $(20 \mu \mathrm{M})$ or NAC $(5 \mathrm{mM})$ in serumfree media for $24 \mathrm{~h}$. In another group, cells were pretreated with BSO $(0.25 \mathrm{mM})$ for $1 \mathrm{~h}$ before addition of insulin $(100 \mathrm{nM})$ and curcumin $(20 \mu \mathrm{M})$ or NAC $(5 \mathrm{mM})$ in serumfree media for additional $24 \mathrm{~h}$. Total RNA and whole cell extracts were prepared. As shown using real-time PCR (Figure 9a) and Western blotting analyses (Figure 9b), compared with the untreated controls (the corresponding first columns and wells), insulin increased, as expected, the levels of mRNA and proteins of InsR and other key genes relevant to HSC activation (the corresponding second columns and wells), including $\alpha \mathrm{I}(\mathrm{I})$ collagen, $\alpha$-SMA and promitogenic PDGF- $\beta$ R and EGFR, as well as pro-fibrogenic T $\beta$ RI and T $\beta$-RII and CTGF. NAC (the fourth columns and wells) mimicked the role of curcumin (the third columns and wells) and dramatically eliminated the inhibitory effect of insulin on the expression of InsR and the other key genes relevant to HSC activation. The depletion of intracellular GSH by pretreatment with BSO apparently eliminated the effects of both curcumin (the sixth columns and wells)and NAC (the seventh columns and wells) on the suppression of expression of the genes, including InsR, in activated HSCs in vitro. Taken together, these results showed that de novo 

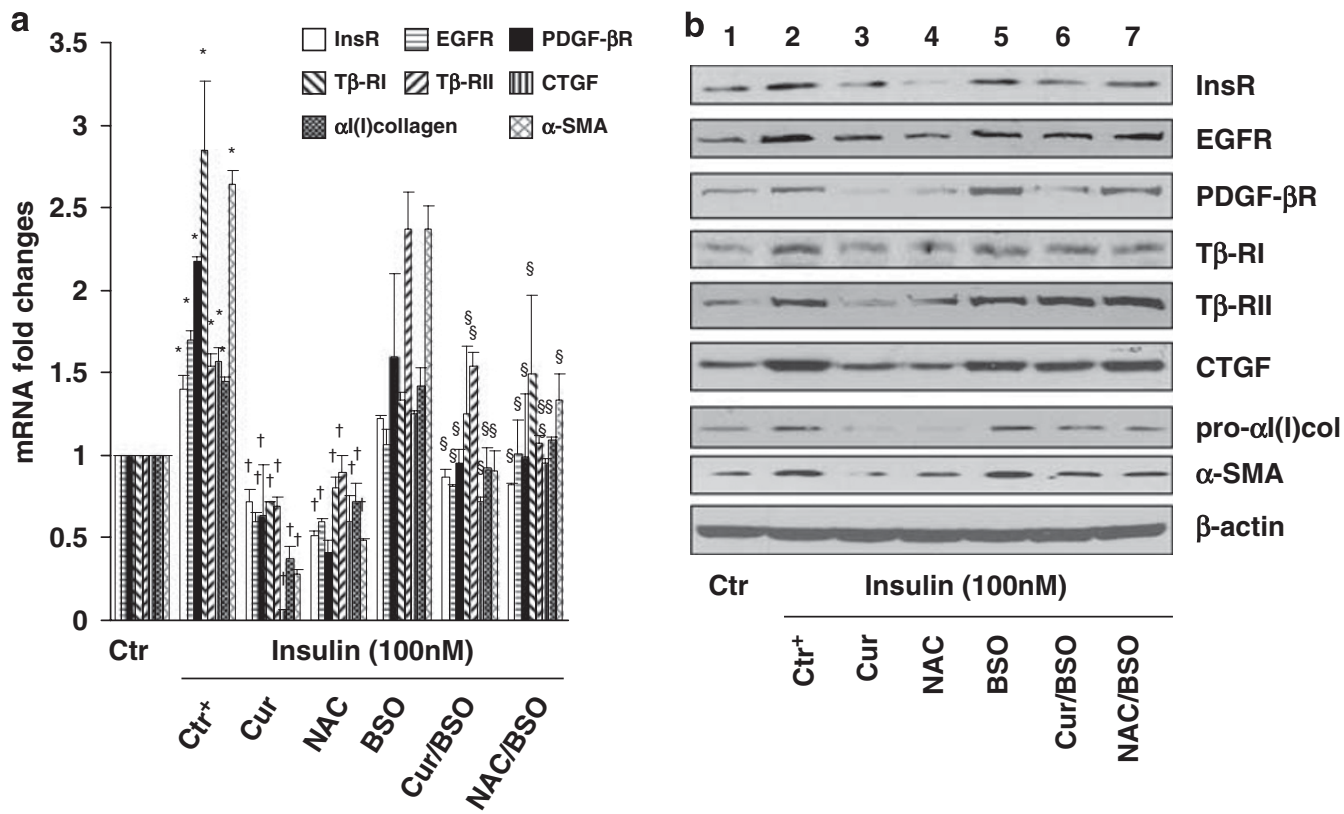

Figure 9 De novo synthesis of GSH is required for curcumin to suppress gene expression of InsR and other proteins relevant to HSC activation induced by insulin. Serum-starved HSCs were divided into two groups. One group of cells was treated with or without insulin ( $100 \mathrm{nM})$ and curcumin (Cur) (20 $\mu \mathrm{M})$ or NAC $(5 \mathrm{mM})$ in serum-free media for $24 \mathrm{~h}$. Another group of cells was pretreated with BSO $(0.25 \mathrm{mM})$ for $1 \mathrm{hr}$ before addition of insulin (100 $\mathrm{nM})$ and curcumin $(20 \mu \mathrm{M})$ or NAC $(5 \mathrm{mM})$ in serum-free media for additional $24 \mathrm{~h}$. Total RNA or whole cell extracts were respectively prepared for real-time PCR assays (a) or for Western blotting analyses (b). $\beta$-actin was used as an invariant internal control for calculating mRNA fold changes $(n=3)$. ${ }^{*}<0.05$ versus cells with no treatment (the first column); ${ }^{\dagger} P<0.05$ versus cells treated with insulin only (the second column); ${ }^{\S} P<0.05$ versus cells treated with insulin and Cur (the third columns) or NAC (the fourth columns). $\beta$-actin was used as an internal control for equal loading (b). Blots were representatives from three independent Western blotting analyses experiments.

synthesis of GSH was required for curcumin to inhibit gene expression of InsR and other key proteins relevant to HSC activation induced by insulin.

\section{DISCUSSION}

Development of steatosis, steatohepatitis and fibrosis is a common outcome of type II diabetic patients with hyperinsulinemia. A large number of studies have focused on the effect of the elevated levels of insulin on hepatocytes. ${ }^{2}$ However, very few studies have addressed the effects of the elevated levels of insulin on activation of HSCs, which are targets and responding cells to pathological insults in the state of hyperinsulinemia. ${ }^{2}$ Previous studies suggested that insulin stimulated HSC activation in vitro by inducing mitogenesis and collagen synthesis. ${ }^{12}$ The underlying mechanisms remain largely to be defined. Curcumin has received attention as a promising dietary component for the protection against fibrogenic insults. ${ }^{18}$ The current study was designed to evaluate the effect of curcumin on eliminating the role of insulin in the stimulation of HSC activation and to further elucidate the underlying mechanisms. Our results suggested that curcumin eliminated the role of insulin in stimulating HSC activation. Curcumin interrupted insulin signaling in HSCs by reducing the phosphorylation levels of InsR and downstream inter-mediators and by dramatically suppressing gene expression of InsR. Additional experiments showed that phytochemical attenuated insulin-induced oxidative stress in HSCs by increasing the activity of GCL and stimulating de novo synthesis of GSH. The latter was required for curcumin to suppress expression of InsR and other genes relevant to HSC activation.

Insulin signaling is initiated by the binding of insulin to InsR and subsequently activating downstream signaling cascades. We postulated that InsR might be the first target for curcumin to interrupt insulin signaling. Our results supported the postulation and showed that curcumin exerted its action in two steps. Curcumin eliminated the instant action of insulin by reducing the phosphorylation levels of InsR and its downstream inter-mediators, including ERK, JNK, PI3K and AKT (Figure 3). This action was for a short term. On the other hand, curcumin suppressed gene expression of InsR, leading to the reduction in the bioavailability of InsR to the ligand insulin (Figure 4). This action was slower, but lasted longer, not less than $24 \mathrm{~h}$. Previous studies have shown similar functions of curcumin in interrupting signal transduction pathways for PDGF, EGF and TGF- $\beta .^{20,28,35}$ Curcumin reduced the phosphorylation levels of PDGF- $\beta$ R and TGF- $\beta$ receptors, as well as suppressed gene expression of the receptors in activated HSCs in vitro. These results suggest that curcumin might be a broad-spectrum inhibitor and non-specifically interrupts signaling pathways involved in the activation of HSCs. The underlying mechanisms remain 
elusive. Other studies have indicated the role of GSH in the physiological modulation of protein tyrosine phosphatase $1 \mathrm{~B}$, a key enzyme in the downregulation of insulin signaling. ${ }^{36}$ We previously observed that it took several hours for curcumin to increase the level of cellular GSH in HSCs, ${ }^{26}$ because the process required the transcription and translation of GCL genes. As curcumin rapidly reduced the phosphorylation levels of InsR and the downstream inter-mediators, it is unlikely that the inhibitory effect of curcumin results from its capability to elevate the level of cellular GSH. We recently observed that curcumin instantly and dramatically reduced the level of cellular $\mathrm{Ca}^{+}{ }^{+}$in cultured HSCs (unpublished observations by Lin and Chen). Accumulating evidence has indicated the role of calcium in regulation of the activities of protein tyrosine kinases and phosphatases. ${ }^{37-39}$ Additional experiments are necessary to explore the mechanisms by which curcumin acts as a protein tyrosine kinase inhibitor and/or a phosphatase activator to reduce the phosphorylation levels of InsR and downstream signaling inter-mediators.

A critical question was raised while performing our pilot experiments whether curcumin would interrupt the insulin signaling in other insulin-responding cells, including hepatocytes and muscle cells. If so, curcumin would deteriorate hyperglycemia and diabetes. It is noteworthy that curcumin has shown distinct effects on regulating gene expression depending on cell types. ${ }^{40}$ Curcumin induces gene expression of low-density lipoprotein receptor (LDLR) in hepatoma cell line, HepG $2,{ }^{41}$ which might result in an increase in the endocytosis of plasma LDL by hepatocytes and a reduction in the level of plasma LDL. However, curcumin suppresses gene expression of LDLR in cultured $\mathrm{HSCs}^{42}$ which attenuates the stimulatory role of LDL in the activation of HSCs. Curcumin and its major metabolite increase the number of total cellular insulin-binding sites in circulating erythrocytes in a streptozotocin-induced diabetic rat model. ${ }^{43}$ In addition, curcumin significantly reduces blood glucose levels and improves insulin resistance, glucose tolerance as well as lipid profiles in $d b / d b$ mice. ${ }^{44}$ Current available results, together with our pilot observations, have suggested that curcumin has anti-hyperglycemic and antidiabetic effects in diabetic animal models. ${ }^{44-47}$ Although beyond the scope of this report, it is of interest to address the underlying mechanisms by which curcumin shows distinct effects on different cell types, including HSCs and hepatocytes.

Curcumin is a potent antioxidant whose antioxidant capacity is 100 -fold stronger than vitamin $\mathrm{E} / \mathrm{C} .{ }^{17}$ The underlying mechanisms are largely undefined. NAC, as an antioxidant, has been studied to inhibit hepatic fibrosis in animal models. ${ }^{48-50}$ However, results are not always promising and consistent. It is noteworthy that compared with the effects of curcumin at $20 \mu \mathrm{M}, \mathrm{NAC}$ at a much higher concentration $(5 \mathrm{mM})$ showed similar, if not weaker, effects on the attenuation of the insulin-stimulatory effects
(Figure 9). This observation suggested that curcumin, compared with NAC, might act in a unique and more efficient mechanism to exert its antioxidant properties. In general, one molecule of a 'regular' antioxidant, such as vitamin E, directly scavenges one or two free radicals, leading to the attenuation of oxidative stress. In this report, we observed that curcumin indirectly attenuated oxidative stress by inducing gene expression of GCL, a key rate-limiting enzyme in de novo synthesis of GSH. The enhanced GCL activity catalyzes de novo synthesis of GSH, resulting in the removal of many molecules of ROS and the reduction of LPO production induced by insulin in HSCs. This unique mechanism explains, at least partially, its potent antioxidant capacity, which might allow curcumin to succeed where other 'regular' antioxidants have failed to inhibit hepatic fibrogenesis. The level of cellular GSH is mainly determined by GSH synthesis (GSH supply) and GSH-consuming (GSH demand). It bears emphasis that our results do not exclude the role of curcumin in the suppression of GSH-consuming to elevate the level of cellular GSH in activated HSCs.

The toxicity of curcumin to cultured HSCs was previously evaluated. ${ }^{20}$ On the basis of the results from LDH release assays, Trypan blue exclusion assays and a rapid recovery of cell proliferation after withdrawal of curcumin, it was concluded that curcumin up to $100 \mu \mathrm{M}$ was not toxic to cultured HSCs. Curcumin at $20 \mu \mathrm{M}$ was used in most of our experiments in this report. This working concentration of curcumin is in the range used by many other researchers. ${ }^{51-53}$ The systemic bioavailability of curcumin is relatively low. ${ }^{54}$ Curcumin concentrations in human plasma can reach up to $2 \mu \mathrm{M}$ after an oral intake of very high amounts of curcumin. ${ }^{51}$ Although higher concentrations of curcumin in the blood might be possible, depending on the actual composition of the food, ${ }^{54}$ most pharmacokinetic studies in humans point out that only low $\mu$ mol levels of curcumin can be found in the blood. It is noteworthy that because the in vivo system is multi-factorial, directly extrapolating in vitro conditions and results, for example, effective concentrations, to the in vivo system might be misleading.

In summary, our results showed that curcumin attenuated the effects of insulin on stimulating HSC activation, at least partially, by interrupting insulin signaling and attenuating oxidative stress. It bears emphasis that our results do not exclude any other mechanism by which curcumin eliminates the effects of insulin on stimulating HSC activation. Our results in this report suggested that curcumin could be an anti-fibrotic candidate in therapeutic treatment of T2DM and NASH-associated hepatic fibrogenesis.

\section{ACKNOWLEDGEMENT}

The work was supported by the Grant RO1 DK 047995 from NIH/NIDDK to A Chen.

\section{DISCLOSURE/CONFLICT OF INTEREST}

The authors declare no conflict of interest. 
1. Maiese K, Morhan SD, Chong ZZ. Oxidative stress biology and cell injury during type 1 and type 2 diabetes mellitus. Curr Neurovasc Res 2007;4:63-71.

2. Leclercq IA, Da Silva Morais A, Schroyen B, et al. Insulin resistance in hepatocytes and sinusoidal liver cells: mechanisms and consequences. J Hepatol 2007;47:142-156.

3. Dandona P, Aljada A, Chaudhuri A, et al. A novel view of metabolic syndrome. Metab Syndr Relat Disord 2004;2:2-8.

4. Khamzina L, Gruppuso PA, Wands JR. Insulin signaling through insulin receptor substrate 1 and 2 in normal liver development. Gastroenterology 2003;125:572-585.

5. Tsochatzis E, Papatheodoridis GV, Manesis EK, et al. Metabolic syndrome is associated with severe fibrosis in chronic viral hepatitis and non-alcoholic steatohepatitis. Aliment Pharmacol Ther 2008;27:80-89.

6. Clark JM. The epidemiology of nonalcoholic fatty liver disease in adults. J Clin Gastroenterol 2006;40(Suppl 1):S5-S10.

7. Friedman SL. Mechanisms of hepatic fibrogenesis. Gastroenterology 2008;134:1655-1669.

8. Kisseleva T, Brenner DA. Hepatic stellate cells and the reversal of fibrosis. J Gastroenterol Hepatol 2006;21(Suppl 3):S84-S87.

9. Hendriks HF, Brekelmans PJ, Buytenhek R, et al. Liver parenchymal cells differ from the fat-storing cells in their lipid composition. Lipids 1987;22:266-273.

10. Yamada M, Blaner WS, Soprano DR, et al. Biochemical characteristics of isolated rat liver stellate cells. Hepatology 1987;7:1224-1229.

11. Friedman SL, Rockey DC, McGuire RF, et al. Isolated hepatic lipocytes and Kupffer cells from normal human liver: morphological and functional characteristics in primary culture. Hepatology 1992;15: 234-243.

12. Svegliati-Baroni G, Ridolfi F, Di Sario A, et al. Insulin and insulin-like growth factor- 1 stimulate proliferation and type I collagen accumulation by human hepatic stellate cells: differential effects on signal transduction pathways. Hepatology 1999;29:1743-1751.

13. Di Sario A, Candelaresi C, Omenetti A, et al. Vitamin E in chronic liver diseases and liver fibrosis. Vitam Horm 2007;76:551-573.

14. Das KS, Balakrishnan V, Mukherjee $S$, et al. Evaluation of blood oxidative stress-related parameters in alcoholic liver disease and nonalcoholic fatty liver disease. Scand J Clin Lab Invest 2008;68:323-334.

15. Halliwell B. Drug antioxidant effects. A basis for drug selection? Drugs 1991;42:569-605.

16. Svegliati-Baroni G, De Minicis S, Marzioni M. Hepatic fibrogenesis in response to chronic liver injury: novel insights on the role of cell-to-cell interaction and transition. Liver Int 2008;28:1052-1064.

17. Sreejayan N, Rao MN. Curcuminoids as potent inhibitors of lipid peroxidation. J Pharm Pharmacol 1994;46:1013-1016.

18. O'Connell MA, Rushworth SA. Curcumin: potential for hepatic fibrosis therapy? Br J Pharmacol 2008;153:403-405.

19. Fu Y, Zheng S, Lin J, et al. Curcumin protects the rat liver from CCl4caused injury and fibrogenesis by attenuating oxidative stress and suppressing inflammation. Mol Pharmacol 2008;73:399-409.

20. Xu J, Fu Y, Chen A. Activation of peroxisome proliferator-activated receptor-gamma contributes to the inhibitory effects of curcumin on rat hepatic stellate cell growth. Am J Physiol Gastrointest Liver Physiol 2003;285:G20-G30.

21. Zheng $S$, Chen A. Activation of PPARgamma is required for curcumin to induce apoptosis and to inhibit the expression of extracellular matrix genes in hepatic stellate cells in vitro. Biochem J 2004;384: 149-157.

22. Zheng $\mathrm{S}$, Chen A. Curcumin suppresses the expression of extracellular matrix genes in activated hepatic stellate cells by inhibiting gene expression of connective tissue growth factor. Am J Physiol Gastrointest Liver Physiol 2006;290:G883-G893.

23. Chen A, Zhang L. The antioxidant (-)-epigallocatechin-3-gallate inhibits rat hepatic stellate cell proliferation in vitro by blocking the tyrosine phosphorylation and reducing the gene expression of platelet-derived growth factor-beta receptor. J Biol Chem 2003;278:23381-23389.

24. Schmittgen TD, Zakrajsek BA, Mills AG, et al. Quantitative reverse transcription-polymerase chain reaction to study mRNA decay: comparison of endpoint and real-time methods. Anal Biochem 2000;285:194-204.
25. Lin J, Chen A. Activation of peroxisome proliferator-activated receptorgamma by curcumin blocks the signaling pathways for PDGF and EGF in hepatic stellate cells. Lab Invest 2008:88:529-540.

26. Zheng S, Yumei F, Chen A. De novo synthesis of glutathione is a prerequisite for curcumin to inhibit hepatic stellate cell (HSC) activation. Free Radic Biol Med 2007;43:444-453.

27. Fraser JA, Kansagra $P$, Kotecki $C$, et al. The modifier subunit of Drosophila glutamate-cysteine ligase regulates catalytic activity by covalent and noncovalent interactions and influences glutathione homeostasis in vivo. J Biol Chem 2003;278:46369-46377.

28. Zhou Y, Zheng S, Lin J, et al. The interruption of the PDGF and EGF signaling pathways by curcumin stimulates gene expression of PPARgamma in rat activated hepatic stellate cell in vitro. Lab Invest 2007;87:488-498.

29. De Minicis S, Brenner DA. Oxidative stress in alcoholic liver disease: role of NADPH oxidase complex. J Gastroenterol Hepatol 2008;23(Suppl 1):S98-S103.

30. Wu G, Fang YZ, Yang S, et al. Glutathione metabolism and its implications for health. J Nutr 2004;134:489-492.

31. Fridovich I. The biology of oxygen radicals. Science 1978;201: 875-880.

32. Jones DP. Redox potential of GSH/GSSG couple: assay and biological significance. Methods Enzymol 2002;348:93-112.

33. Cotgreave IA. N-acetylcysteine: pharmacological considerations and experimental and clinical applications. Adv Pharmacol 1997;38:205-227.

34. Anderson ME, Luo JL. Glutathione therapy: from prodrugs to genes. Semin Liver Dis 1998;18:415-424.

35. Zheng $\mathrm{S}$, Chen A. Disruption of transforming growth factor-beta signaling by curcumin induces gene expression of peroxisome proliferator-activated receptor-gamma in rat hepatic stellate cells. Am J Physiol Gastrointest Liver Physiol 2007;292:G113-G123.

36. Mueller AS, Bosse AC, Most E, et al. Regulation of the insulin antagonistic protein tyrosine phosphatase $1 \mathrm{~B}$ by dietary Se studied in growing rats. J Nutr Biochem 2008;20:235-247.

37. Gerthoffer WT. Signal-transduction pathways that regulate visceral smooth muscle function. III. Coupling of muscarinic receptors to signaling kinases and effector proteins in gastrointestinal smooth muscles. Am J Physiol Gastrointest Liver Physiol 2005;288: G849-G853.

38. Nilsson BO, Gomez MF, Sward K, et al. Regulation of Ca2+ channel and phosphatase activities by polyamines in intestinal and vascular smooth muscle-implications for cellular growth and contractility. Acta Physiol Scand 2002;176:33-41.

39. Tani E, Matsumoto T. Continuous elevation of intracellular $\mathrm{Ca} 2+$ is essential for the development of cerebral vasospasm. Curr Vasc Pharmacol 2004;2:13-21.

40. Syng-Ai C, Kumari AL, Khar A. Effect of curcumin on normal and tumor cells: role of glutathione and bcl-2. Mol Cancer Ther 2004;3:1101-1108.

41. Peschel D, Koerting R, Nass N. Curcumin induces changes in expression of genes involved in cholesterol homeostasis. J Nutr Biochem 2007; 18:113-119.

42. Kang Q, Chen A. Curcumin suppresses gene expression of low-density lipoprotein receptor, leading to the inhibition of LDL-induced activation of hepatic stellate cell. Brit J Pharmacol 2009;157:1354-1367.

43. Murugan $P$, Pari L, Rao CA. Effect of tetrahydrocurcumin on insulin receptor status in type 2 diabetic rats: studies on insulin binding to erythrocytes. J Biosci 2008;33:63-72.

44. Seo KI, Choi MS, Jung UJ, et al. Effect of curcumin supplementation on blood glucose, plasma insulin, and glucose homeostasis related enzyme activities in diabetic $\mathrm{db} / \mathrm{db}$ mice. Mol Nutr Food Res 2008;52:995-1004

45. Suryanarayana $P$, Saraswat $M$, Mrudula $T$, et al. Curcumin and turmeric delay streptozotocin-induced diabetic cataract in rats. Invest Ophthalmol Vis Sci 2005;46:2092-2099.

46. Pari L, Murugan P. Effect of tetrahydrocurcumin on blood glucose, plasma insulin and hepatic key enzymes in streptozotocin induced diabetic rats. J Basic Clin Physiol Pharmacol 2005;16:257-274.

47. Sharma S, Kulkarni SK, Chopra K. Curcumin, the active principle of turmeric (Curcuma longa), ameliorates diabetic nephropathy in rats. Clin Exp Pharmacol Physiol 2006;33:940-945. 
48. Galicia-Moreno M, Rodriguez-Rivera A, Reyes-Gordillo K, et al. Nacetylcysteine prevents carbon tetrachloride-induced liver cirrhosis: role of liver transforming growth factor-beta and oxidative stress. Eur J Gastroenterol Hepatol 2009;21:908-914.

49. Pereira-Filho G, Ferreira C, Schwengber A, et al. Role of Nacetylcysteine on fibrosis and oxidative stress in cirrhotic rats. Arq Gastroenterol 2008;45:156-162.

50. Tahan G, Tarcin O, Tahan V, et al. The effects of N-acetylcysteine on bile duct ligation-induced liver fibrosis in rats. Dig Dis Sci 2007;52:3348-3354.

51. Garcea G, Jones DJ, Singh R, et al. Detection of curcumin and its metabolites in hepatic tissue and portal blood of patients following oral administration. Br J Cancer 2004;90:1011-1015.
52. Motterlini R, Foresti R, Bassi R, et al. Curcumin, an antioxidant and antiinflammatory agent, induces heme oxygenase- 1 and protects endothelial cells against oxidative stress. Free Radic Biol Med 2000;28:1303-1312.

53. Shakibaei M, John T, Schulze-Tanzil G, et al. Suppression of NF-kappaB activation by curcumin leads to inhibition of expression of cyclooxygenase-2 and matrix metalloproteinase- 9 in human articular chondrocytes: Implications for the treatment of osteoarthritis. Biochem Pharmacol 2007;73:1434-1445.

54. Sharma RA, McLelland HR, Hill KA, et al. Pharmacodynamic and pharmacokinetic study of oral Curcuma extract in patients with colorectal cancer. Clin Cancer Res 2001;7:1894-1900. 